\title{
Components of the alternative complement pathway in patients with psoriasis
}

\author{
Betul Sereflican $^{1 \bowtie}$, Guler Bugdayci² $^{2}$
}

\begin{abstract}
Introduction: Psoriasis is a chronic inflammatory skin disease. Adipose tissue plays important roles in the events that regulate body metabolism. This study determined the levels of complement $3\left(C_{3}\right)$, acylation-stimulating protein (ASP), and adipsin, which take part in the alternate complement pathway, and are synthesized in and secreted by adipose tissue.

Methods: Thirty-two patients with psoriasis were matched with 22 controls in terms of age, sex, body mass index, and lipid profiles. Serum $\mathrm{C}_{3}$, ASP, and adipsin levels were measured in both groups.

Results: The serum $C_{3}$ level was higher and ASP and adipsin levels were lower in the patient group, but these differences were not significant ( $p=0.708, p=0.628$, and $p=0.218$, respectively). ASP and adipsin levels were correlated positively in patients with psoriasis $(p=0.029)$.

Conclusion: To our knowledge, this study is the first to evaluate ASP and adipsin levels in patients with psoriasis. The roles of ASP and adipsin in the etiopathogenesis of psoriasis are unclear. Although not statistically significant, the lower ASP and adipsin levels in the patient group suggest a potential anti-inflammatory role of these proteins in psoriasis. Further studies should examine the relationships between ASP/adipsin and psoriasis.
\end{abstract}

Keywords: alternative complement pathway, psoriasis

Received: 27 February 2017 | Returned for modification: 10 April 2017 | Accepted: 9 May 2017

\section{Introduction}

Psoriasis is a chronic inflammatory disease that is thought to be caused by the combined effects of genetic and environmental factors on the immune system (1). Cutaneous T cells, interleukins, cytokines, and adipokines are activated to induce an inflammatory reaction with altered keratinocyte differentiation and vascular modifications $(2,3)$.

Adipose tissue has recently been recognized to play an important role in controlling the metabolism by producing and secreting various pro- and anti-inflammatory proteins, cytokines, and chemokines. Adipocytes synthesize and release adipokines and complement components that modulate the endocrine system, immunity, and inflammation, such as adiponectin, leptin, visfatin, adipsin, complement $3\left(\mathrm{C}_{3}\right)$, and acylation-stimulating protein (ASP) $(4,5)$. ASP is identical to C3adesArg, the inactive fragment of the complement anaphylatoxin peptide, $\mathrm{C}_{3}$. It is derived from the interaction of $\mathrm{C}_{3}$, adipsin, and factor $\mathrm{B}$ (6). Its primary bioactivities involve the stimulation of triglyceride synthesis and fatty acid storage (7). ASP levels are increased in humans with obesity, diabetes, and cardiovascular diseases (5). In cell models, physiological doses of ASP have inflammatory effects in adipose tissue, especially in terms of cytokine secretion (8). Adipsin (complement $\mathrm{D}$ ) is a complement pathway protein that is produced and secreted by adipose tissue. Complement factor $\mathrm{B}$ and adipsin are essential for the formation of $\mathrm{C}_{3}$ a from $\mathrm{C}_{3}$, leading to the production of ASP. The adipsin level is reduced in obese mice (9), but elevated in obese humans (10). Adipsin is the rate-limiting molecule in the transformation of ASP. The adipsin-ASP system might regulate triglyceride metabolism by ensuring lipid storage $(11,12)$. The liver was long thought to be the principal site of $\mathrm{C}_{3}$ synthesis, but human adipose tissue has been shown to produce and secrete as much $\mathrm{C}_{3}$ as the liver (6). $\mathrm{C}_{3}$ is a key factor in the complement system and its synthesis is enhanced with inflammation. The development of atherosclerosis, high blood pressure, diabetes, obesity, high cholesterol, and coronary heart disease is thought to be associated with $\mathrm{C}_{3}(13,14)$.

The proteins $\mathrm{C}_{3}$, ASP, and adipsin are all components of the complement system; in particular, the alternative complement pathway. Complement factors are generated and regulated in adipose tissue and play roles in metabolic events and the inflammatory response $(6,15)$.

In this study, we determined the levels of $\mathrm{C}_{3}$, ASP, and adipsin in patients with psoriasis and healthy controls to explore the relationships to psoriasis and disease severity. To our knowledge, this study is the first to explore the relationships among $\mathrm{C}_{3}$, adipsin, ASP, and psoriasis.

\section{Materials and methods}

We enrolled 32 patients that had visited our dermatology clinic and had been diagnosed histopathologically with psoriasis, and 22 healthy subjects as the control group. The exclusion criteria for both groups were age $<18$ years, diagnosis of erythrodermic or pustular psoriasis with only palmoplantar involvement, and receipt of any systemic treatment for psoriasis or phototherapy in the previous 3 months. Subjects with psoriatic arthritis, any systemic disease, receipt of treatment, or any infection in the 4 weeks before the study were also excluded. The control group was selected from subjects of similar age, sex, and body mass index (BMI) to the patient group. The type of psoriasis, disease duration, and medication history were noted for each participant. The Psoriasis Area Severity Index (PASI) was used to evaluate the severity of the disease. 
Peripheral blood samples were obtained from both groups after fasting for at least $12 \mathrm{~h}$. The blood samples were centrifuged at $1,500 \mathrm{~g}$ for $10 \mathrm{~min}$ and the serum was stored at $-70{ }^{\circ} \mathrm{C}$ until analysis. Blood samples were used to determine fasting glucose, fasting cholesterol, triglyceride (TG), high-density lipoprotein (HDL), low-density lipoprotein (LDL), adipsin, ASP, and C3 levels.

The Sunred Human ASP ELISA kit (catalog no. 201-12-1485; Sunred, Shanghai, China) was used to measure serum ASP levels. The intra-assay variability was $<10 \%$ and the interassay variability was $<12 \%$.

The Sunred Human Adipsin (CFD) ELISA kit (catalog no. 201-120320) was used to measure serum adipsin levels. Samples were diluted 1:40 in physiological saline. The intra-assay variability was $<8 \%$ and the interassay variability was $<10 \%$.

Serum $\mathrm{C}_{3}$ levels were measured using a turbidimetric immunoassay in an Architect c80oo autoanalyzer (Abbott, Lake Bluff, IL, USA).

Serum LDL cholesterol levels were measured using an enzymatic method (Archem, Istanbul, Turkey) in an Architect c8ooo autoanalyzer.

Fasting glucose, fasting cholesterol, TG, and HDL levels were measured by enzymatic methods in an Architect c80oo autoanalyzer.

Ethics approval for the study was received from the Clinical Research Ethics Committee of Abant İzzet Baysal University on July 23rd, 2015 (no. 2015/61). Written informed consent was obtained from all participants.

An independent-samples $t$-test was used to compare normally distributed data from the two groups. For non-normally distributed data, the Mann-Whitney $U$-test was used to establish differences between groups. Correlations were evaluated using the Pearson correlation test. In all statistical tests, $p$ values $<0.05$ were considered to be statistically significant.

\section{Results}

The study included 32 patients (20 females, 12 males) with psoriasis and 22 healthy individuals ( 19 females, 3 males). The patients with psoriasis and healthy subjects were matched based on age, sex, and BMI ( $p=0.105,0.054$, and 0.054, respectively; Table 1).

In the patient group, the median duration of disease was 78 (3-516) months and the median PASI score was 4.4 (0.7-19.8).

The mean $\mathrm{C}_{3}$ levels in the patient and control groups were $111.66 \pm 27.320$ and $109.1 \pm 20.0 \mathrm{mg} / \mathrm{dl}$, respectively. The difference was not significant $(p=0.708)$. No significant correlation was observed between the PASI score and $\mathrm{C}_{3}$ level $(p=0.624)$.

The median ASP levels in the patient and control groups were $39.842(30.9-253.1)$ and $65.2(21.6-193.5) \mathrm{nmol} / 1$, respectively (Figure 1). The difference was not significant $(p=0.628)$. The PASI score and ASP level were not correlated in the patient group $(p=0.616)$.

The median adipsin levels in the patient and control groups were 1917.9 (1468.5-4894.5) and $1932.5(1576.4-6596.5) \mathrm{ng} / \mathrm{ml}$, re-

Table 1 | Demographics and laboratory findings of patients with psoriasis and healthy individuals.

\begin{tabular}{lccc}
\hline Characteristic & Psoriasis patient & ${ }^{\star}$ Control subjects & $p$ value \\
\hline Age, yrs & $28(18-55)$ & $24(19-37)$ & 0.105 \\
Male, $n$ (\%), female, $n$ (\%) & $12(37.5), 20(62.5)$ & $3(13.6), 19(86.4)$ & 0.054 \\
BMI & $25.25(17.17-30.10)$ & $21.25(17.30-28.20)$ & 0.054 \\
Disease duration, months & $78(3-516)$ & - & \\
PASI & $4.4(0.7-19.8)$ & - & 0.217 \\
TC, mg/dl & $181.59 \pm 38.63$ & $169.23 \pm 30.96$ & 0.205 \\
TG, mg/dl & $118.0(40-349)$ & $91.50(50-311)$ & 0.151 \\
LDL, mg/dl & $74.66 \pm 26.66$ & $83.41 \pm 17.42$ & 0.342 \\
HDL, mg/dl & $48.65 \pm 14.14$ & $52.25 \pm 12.71$ & 0.000 \\
CRP, mg/l & $3.08(0.1-26.1)$ & $0.2(0.1-5.6)$ & 0.064 \\
Glucose, mg/dl & $94.59 \pm 8.63$ & $90.09 \pm 8.49$ & 0.708 \\
C3, mg/dl & $111.66 \pm 27.32$ & $109.09 \pm 20.00$ & 0.628 \\
ASP, $\mathrm{nmol} / \mathrm{l}$ & $39.84(30.90-253.09)$ & $65.22(21.59-193.48)$ & 0.218 \\
Adipsin, $\mathrm{ng} / \mathrm{ml}$ & $1,917.85(1,468.49-4,894.53)$ & $1,932.45(1,576.36-6,596.35)$ & 0.35 \\
\hline
\end{tabular}

$\mathrm{BMI}=$ body mass index, $\mathrm{PASI}=$ psoriasis area and severity index, TC $=$ total cholesterol, $\mathrm{TG}=$ triglyceride, $\mathrm{LDL}=$ low density lipoprotein, $\mathrm{HDL}=\mathrm{high}$ density lipoprotein, CRP $=$ C-reactive protein, $\mathrm{C} 3=$ complement $3, \mathrm{ASP}=$ acylation-stimulating protein.

${ }^{\star}$ Normally distributed data are reported as mean \pm standard deviation and compared with a $t$-test; asymmetrically distributed data are reported as median (ranges) and compared with the Mann-Whitney $U$-test.

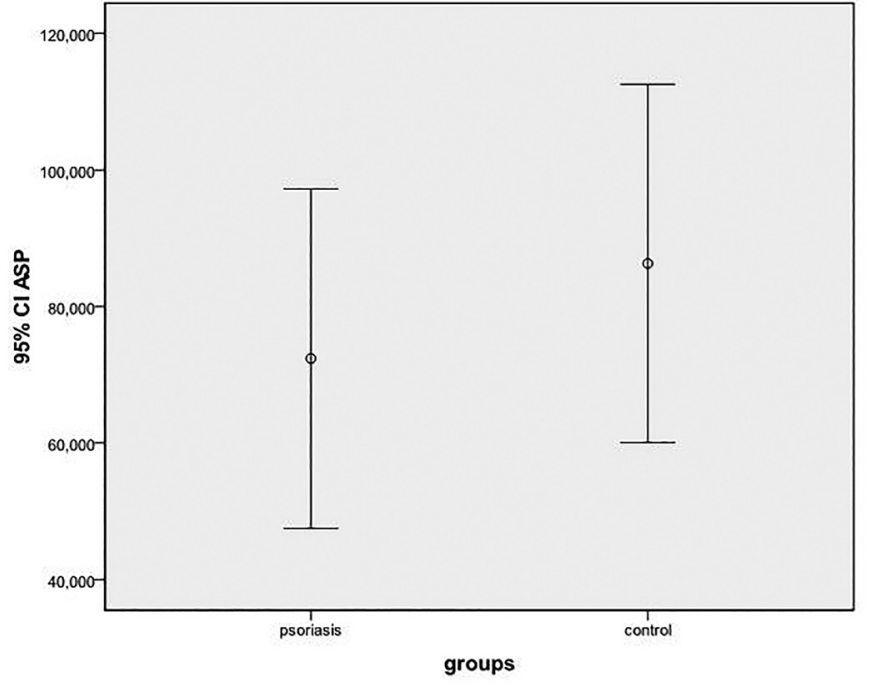

Figure 1 | 95\% confidence interval (CI) for acylation-stimulating protein (ASP) in patients and healthy individuals.

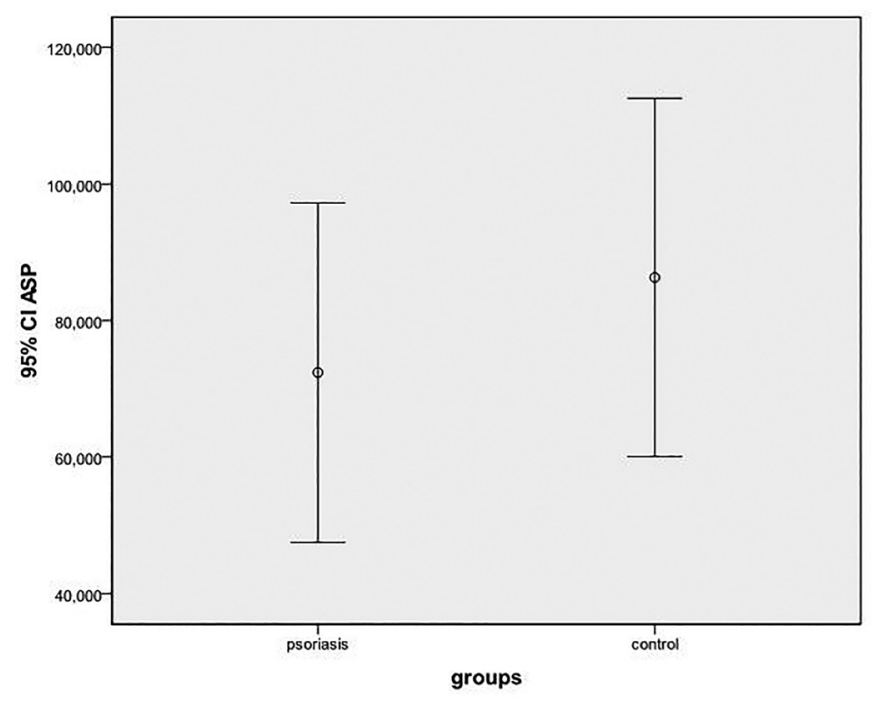

Figure 2 | 95\% confidence interval (Cl) for adipsin in patients and healthy individuals. 
spectively (Figure 2). The difference was not significant $(p=0.218)$. The PASI score and adipsin level were not correlated ( $p=0.741)$.

No significant difference in parameters that might affect adipokine levels, such as lipid profile and glucose concentration, was observed between the patients with psoriasis and controls. However, the acute-phase reactant C-reactive protein (CRP) level differed significantly between groups ( $p=0.000$; Table 1 ).

The alternative complement pathway components were not correlated with age, disease duration, BMI, or CRP level (all $p>$ 0.05). The ASP and adipsin levels were also not correlated with the lipid profile or glucose concentration in the patient group. Nevertheless, the $C_{3}$ level was correlated positively with TG, LDL, cholesterol, and glucose levels in the patient group $(r=0.514, p=$ $0.003 ; r=0.722, p=0.000 ; r=0.395, p=0.025 ; r=0.433, p=0.013$, respectively). The $\mathrm{C}_{3}$ level was also correlated positively with BMI in all subjects ( $r=0.409, p=0.003)$, and a significant positive correlation between the ASP and adipsin levels was observed in patients with psoriasis $(p=0.029)$.

\section{Discussion}

Complement components are associated with cellular immune responses, cancer, coagulation, atherosclerosis, and low-grade inflammation. Three different complement pathways have been defined: the classical, alternative, and lectin pathways. These pathways are triggered by various factors (16). $C_{3}, C_{5}, C_{3} a, C_{5} a$, and ASP are the major components of the complement cascade that affect metabolic reactions. In the alternative complement pathway, $\mathrm{C}_{3} \mathrm{~b}$ reacts with the proteins factor $\mathrm{B}$, adipsin, and properdin to compose $\mathrm{C}_{3}$ convertase. $\mathrm{C}_{3}$ convertase cleaves $\mathrm{C}_{3}$ into $\mathrm{C}_{3} \mathrm{a}$ and $\mathrm{C}_{3} \mathrm{~b}$. $\mathrm{C}_{3} \mathrm{~b}$ associates with $\mathrm{C}_{3} \mathrm{bBb}$ to form $\mathrm{C}_{5}$ convertase, which cleaves $\mathrm{C}_{5}$ into $\mathrm{C}_{5}$ a and $\mathrm{C}_{5}$ b. $\mathrm{C}_{3}$ a moves as an anaphylotoxin. ASP is generated from $\mathrm{C}_{3}$ a via carboxypeptidase N. Carboxypeptidase $\mathrm{N}$ was reported to disrupt the activity of the anaphylatoxin $\mathrm{C}_{3} \mathrm{a}$ because ASP cannot mediate many of the proinflammatory activities associated with $\mathrm{C}_{3} \mathrm{a}(17,18)$. Adipsin plays a key role in the alternative pathway (19). Some studies have examined $C_{3}$ levels in patients with psoriasis. Rocha-Pereira et al. (20) found that the serum $C_{3}$ level was significantly elevated in patients with active and inactive psoriasis; although BMI, age, and sex were similar in the patient and control groups in their study, they provided no information on lipid profiles in either group. Torres et al. (21) found that the $\mathrm{C}_{3}$ level was increased in patients with psoriasis compared with controls. In their study, the BMI was significantly higher in the psoriasis group, although the lipid profile did not differ between groups. Alpsoy et al. (22) reported that the serum C3 level was elevated and correlated with aortic strain, compliance, and stiffness in patients with psoriasis. Schonthaler et al. (23) found $\mathrm{C}_{3}$ expression in psoriatic skin lesions. In our study, although the $\mathrm{C}_{3}$ level was higher in the patient group, the difference was not significant. Our patient and control groups did not differ significantly in terms of age, sex, BMI, lipid profile, or glucose concentration, all of which may influence the $C_{3}$ level. This matching increases the reliability of our results. However, our patients had mild to moderate disease severity and low PASI scores. Consequently, the serum $\mathrm{C}_{3}$ levels may have been lower than anticipated.

$\mathrm{C}_{3} \mathrm{a}$, which is the cleavage product of $\mathrm{C}_{3}$, moderates proinflammatory actions via the $\mathrm{C}_{3}$ a receptor ( $\left.\mathrm{C}_{3} \mathrm{aR}\right)$. Desargination of the carboxyl terminus of $\mathrm{C}_{3}$, leading to the formation of ASP, eliminates the capability to bind to the $\mathrm{C}_{3} \mathrm{aR}$, and hence its biological activity $(6,24)$. The $\mathrm{C}_{5}$-like receptor $2\left(\mathrm{C}_{5} \mathrm{~L}_{2}\right)$ is postulated to be a unique ASP receptor, although some studies found no interaction between $\mathrm{C}_{5} \mathrm{~L}_{2}$ and ASP $(19,25)$. C5a, C5adesArg, and $\mathrm{C}_{3}$ a also bind to $\mathrm{C}_{5} \mathrm{~L} 2$ (24). The $\mathrm{C}_{5} \mathrm{~L} 2$ receptor has different activities in various systems at different times, including both anti- and proinflammatory roles (25). ASP-mediated $\mathrm{C}_{5} \mathrm{~L} 2$ activation triggers $\mathrm{C}_{5} \mathrm{~L} 2$ phosphorylation and $\beta$-arrestin-2-related intracellular endosomes (26). Bamberg et al. (27) showed that the $\mathrm{C}_{5} \mathrm{~L}_{2}-\beta$-arrestin complex has an anti-inflammatory effect. In addition, $\mathrm{C}_{5} \mathrm{~L} 2$ may modulate C5aR-mediated inflammatory processes via feedback mechanisms. Epidermal keratinocytes do not express C5L2 (28). Studies of $\mathrm{C}_{5} \mathrm{~L}_{2}$ and its ligands are ongoing and the $\mathrm{ASP}-\mathrm{C}_{5} \mathrm{~L}_{2}$ interaction and subsequent actions need to be elucidated.

We found no study of the relationship between ASP and psoriasis in the English literature. In a study of patients with psoriatic arthritis, Hermann et al. (29) found a positive correlation between interleukin 1 and ASP, but the authors did not mention high ASP levels in these patients. In our study, the ASP level was lower in patients with psoriasis, but the difference was not significant. Because the C3a level is significantly elevated in patients with psoriasis (30), we speculate that the desargination of $\mathrm{C}_{3}$ a leading to ASP formation is decreased in the inflammatory stage. In addition, abnormal keratinocyte proliferation is a characteristic of psoriasis, and the lack of $\mathrm{C}_{5} \mathrm{~L} 2$ expression on epidermal keratinocytes may explain the low ASP level in the patient group. However, determination of whether these activities are a cause or consequence of psoriasis is difficult because of the cross-sectional nature of our study.

Adipsin is mainly produced by adipose tissue. The level of ASP, which is a cleavage product of $\mathrm{C}_{3}$, may be affected by the initiating enzyme adipsin (6). Legakis et al. (31) found that the adipsin level was significantly decreased in patients with type 2 diabetes compared with healthy individuals. Ciprandi et al. (32) investigated serum adipsin levels in seasonal allergic rhinitis, which is characterized by an inflammatory reaction. They found that this level was increased in allergic patients, albeit not significantly. Interestingly, however, patients treated with sublingual immunotherapy showed a significant increase in adipsin level. Therefore, adipsin appears to have both pro- and anti-inflammatory effects. Gora et al. (33) investigated adipsin in another inflammatory disease, atopic dermatitis in children. Children with atopic dermatitis had significantly lower adipsin activity than normal before treatment. After treatment, the adipsin activity was normal. To our knowledge, no study has examined the relationship between adipsin and psoriasis. We found that the adipsin level was lower in patients with psoriasis, although not significantly. Adipsin levels paralleled ASP levels in our study and were correlated positively, as expected, which increases the reliability of our results.

One limitation of our study was the small number of subjects. Our findings should be confirmed in studies with more patients. Second, because our study was conducted at one center, future multicenter studies are needed.

\section{Conclusion}

Although not statistically significant, the lower ASP and adipsin levels in the patient group suggest potential anti-inflammatory roles of these proteins in psoriasis. Elevated ASP levels have been reported in inflammatory conditions, such as diabetes and cardiovascular disease. However, these diseases are closely associated with TG and glucose metabolism. Larger studies are needed to clarify the relationships between ASP/adipsin levels and cutaneous inflammatory diseases, such as psoriasis. 


\section{Acknowledgment}

This study was supported by the Research Fund of Abant İzzet Baysal University (project no. 2015.08.25.908).

\section{References}

1. Puig-Sanz L. [Psoriasis, a systemic disease?]. Actas Dermosifiliogr. 2007;98: 396-402.

2. Ozkanli S, Zemheri E, Karadag AS, Akbulak O, Zenginkinet T, Zindanci I, et al. A comparative study of histopathological findings in skin biopsies from patients with psoriasis before and after treatment with acitretin, methotrexate and phototherapy. Cutan Ocul Toxicol. 2015;34:276-81.

3. Voiculescu VM, Lupu M, Papagheorghe L, Giurcaneanu C, Micu E. Psoriasis and metabolic syndrome-scientific evidence and therapeutic implications. J Med Life. 2014;7:468-71.

4. Fantuzzi G. Adipose tissue, adipokines, and inflammation. J Allergy Clin Immunol. 2005;115:911-9.

5. Coelho M, Oliveira T, Fernandes R. Biochemistry of adipose tissue: an endocrine organ. Arch Med Sci. 2013;9:191-200.

6. Cianflone K, Xia Z, Chen LY. Critical review of acylation-stimulating protein physiology in humans and rodents. Biochim Biophys Acta. 2003;1609:127-43.

7. Guerre-Millo M. Adipose tissue and adipokines: for better or worse. Diabetes Metab. 2004;30:13-9.

8. Tom FQ, Gauvreau D, Lapointe M, Lu H, Poursharifi P, Luo P, et al. Differential chemoattractant response in adipocytes and macrophages to the action of acylation stimulating protein. Eur J Cell Biol. 2013;92:61-9.

9. Ahima RS, Flier JS. Adipose tissue as an endocrine organ. Trends Endocrinol Metab. 2000;11:327-32.

10. Napolitano A, Lowell BB, Damm D, Leibel RL, Ravussin E, Jimerson DC, et al. Concentrations of adipsin in blood and rates of adipsin secretion by adipose tissue in humans with normal, elevated and diminished adipose tissue mass. Int J Obes Relat Metab Disord. 1994;18:213-8.

11. Baldo A, Sniderman AD, St-Luce S, Avramoglu RK, Maslowska M, Hoang B, et al. The adipsin-acylation stimulating protein system and regulation of intracellular triglyceride synthesis. J Clin Invest. 1993;92:1543-7.

12. Sivakumar K, Bari MF, Adaikalakoteswari A, Guller S, Weickert MO, Randeva HS, et al. Elevated fetal adipsin/acylation-stimulating protein (ASP) in obese pregnancy: novel placental secretion via Hofbauer cells. J Clin Endocrinol Metab. 2013;98:4113-22.

13. Jiang H, Guo M, Dong L, Cao C, Wang D, Liang X, et al. Levels of acylation stimulating protein and the complement component 3 precursor are associated with the occurrence and development of coronary heart disease. Exp Ther Med. 2014;8:1861-6.

14. Engström G, Hedblad B, Eriksson KF, Janzon L, Lindgarde F. Complement $C_{3}$ is a risk factor for the development of diabetes: a population-based cohort study. Diabetes. 2005;54:570-5.

15. Barbu A, Hamad OA, Lind L, Ekdahl KN, Nilsson B. The role of complement factor $C_{3}$ in lipid metabolism. Mol Immunol. 2015;67:101-7.

16. Vlaicu SI, Tatomir A, Boodhoo D, Vesa S, Mircea PA, Rus H. The role of complement system in adipose tissue-related inflammation. Immunol Res. 2016; 64:653-64.

17. Nesargikar PN, Spiller B, Chavez R. The complement system: history, pathways, cascade and inhibitors. Eur J Microbiol Immunol (Bp). 2012;2:103-11.
18. Matthews KW, Drouin SM, Liu C, Martin JF, Skidgel RA, Wetsel RA. Expression of the third complement component $\left(\mathrm{C}_{3}\right)$ and carboxypeptidase $\mathrm{N}$ small subunit (CPN1) during mouse embryonic development. Dev Comp Immunol. 2004;28:647-55.

19. Phieler J, Garcia-Martin R, Lambris JD, Chavakis T. The role of the complement system in metabolic organs and metabolic diseases. Semin Immunol. 2013;25:47-53.

20. Rocha-Pereira P, Santos-Silva A, Rebelo I, Figueiredo A, Quintanilha A, Teixeira F. The inflammatory response in mild and in severe psoriasis. $\mathrm{Br} J$ Dermatol. 2004;150:917-28.

21. Torres T, Bettencourt N, Mendonça D, Vasconcelos C, Silva BM, Selores M. Complement $C_{3}$ as a marker of cardiometabolic risk in psoriasis. Arch Dermatol Res. 2014;306:653-60.

22. Alpsoy S, Akyuz A, Erfan G, Akkoyun DC, Topcu B, Guzel S, et al. Atherosclerosis, some serum inflammatory markers in psoriasis. G Ital Dermatol Venereol. 2014;149:167-75.

23. Schonthaler HB, Guinea-Viniegra J, Wculek SK, Ruppen I, Ximénez-Embún P, Guío-Carrión A, et al. S100A8-S100A9 protein complex mediates psoriasis by regulating the expression of complement factor $C_{3}$. Immunity. 2013;39:1171-81.

24. Köhl J. Anaphylatoxins and infectious and non-infectious inflammatory diseases. Mol Immunol. 2001;38:175-87.

25. Li R, Coulthard LG, Wu MC, Taylor SM, Woodruff TM. C5L2: a controversial receptor of complement anaphylatoxin, C5a. FASEB J. 2013;27:855-64.

26. Cui W, Simaan M, Laporte S, Lodge R, Cianflone K. C5a- and ASP-mediated C5L2 activation, endocytosis and recycling are lost in $\mathrm{S}_{32} \mathrm{I}_{\mathrm{I}} \mathrm{C}_{5} \mathrm{~L} 2$ mutation. Mol Immunol. 2009;46:3086-98.

27. Bamberg CE, Mackay CR, Lee H, Zahra D, Jackson J, Lim YS, et al. The C5a receptor ( $\left.C_{5} \mathrm{aR}\right) \mathrm{C}_{5} \mathrm{~L}_{2}$ is a modulator of $\mathrm{C}_{5}$ aR-mediated signal transduction. J Biol Chem. 2010;285:7633-44.

28. Purwar R, Wittmann M, Zwirner J, Oppermann M, Kracht M, Dittrich-Breiholz O, et al. Induction of $\mathrm{C}_{3}$ and $\mathrm{CCL}_{2}$ by $\mathrm{C}_{3} \mathrm{a}$ in keratinocytes: a novel autocrine amplification loop of inflammatory skin reactions. J Immunol. 2006;177:4444-50.

29. Hermann E, Vogt P, Hagmann W, Dunky A, Müller W. [Synovial level of interleukin 1 and $C_{3}$ in chronic polyarthritis, psoriatic arthritis and activated arthritis]. Z Rheumatol. 1988;47:20-5

30. Kapp A, Wokalek H, Schöpf E. Involvement of complement in psoriasis and atopic dermatitis-measurement of $\mathrm{C}_{3} \mathrm{a}$ and $\mathrm{C}_{5} \mathrm{a}, \mathrm{C}_{3}, \mathrm{C}_{4}$ and $\mathrm{C}_{1}$ inactivator. Arch Dermatol Res. 1985;277:359-61.

31. Legakis I, Mantzouridis T, Bouboulis G, Chrousos GP. Reciprocal changes of serum adispin and visfatin levels in patients with type 2 diabetes after an overnight fast. Arch Endocrinol Metab. 2016;60:76-8.

32. Ciprandi G, De Amici M, Marseglia G. Serum adipsin levels in patients with seasonal allergic rhinitis: preliminary data. Int Immunopharmacol. 2009;9:1460-3.

33. Gora NV, Kozlov LV, Logunov OV, Bashkina OA, Rubalskiĭ OV, Aleshkin VA. Activity of $B$ and $D$ factors of complement alternative pathway in children with atopic dermatitis. Zh Mikrobiol Epidemiol Immunobiol. 2014;3:15-20. 